\title{
LICENCIATURA INTERCULTURAL INDÍGENA: UMA EXPERIÊNCIA DOCENTE EM TERRAS KAINGANG
}

\author{
BERNARD GUEDES DARIVA ${ }^{1}$ \\ UNOCHAPECÓ, BRASIL \\ https://orcid.org/0000-0002-3204-3289 \\ CLÁUDIA BATTESTIN ${ }^{2}$ \\ UNOCHAPECÓ, BRASIL \\ https://orcid.org/0000-0001-7871-9275
}

\begin{abstract}
RESUMO: O presente artigo busca mostrar os desafios e avanços ocorridos durante o processo de formação na licenciatura intercultural indígena no curso de Matemática e Ciências da Natureza em uma universidade comunitária no sul do Brasil com ênfase para a formação em Ciências e Biologia. A metodologia perpassou pela pesquisa bibliográfica, análise documental e realização de entrevistas. A necessidade de compreender a trajetória dos povos indígenas no processo histórico social foi balizadora para compreender a história contemporânea que levou à necessidade de uma educação diferenciada indígena no Brasil. A Licenciatura Intercultural Indigena da Unochapecó vem ao encontro desta necessidade histórica. Para compreendermos melhor como ocorreu esse percurso, entrevistamos três professores(as) que trabalharam durante o processo de formação nesta modalidade, a fim de dar visibilidade às nuances de se trabalhar com a formação de professores em terras indígenas. Durante as entrevistas ficou evidente o grande esforço dos entrevistados em promover práticas interculturais. Contudo, a falta de capacitação inicial se refletiu no discurso que ainda carrega alguns aspectos coloniais. No decorrer do processo formativo, a sensibilização com a temática foi fundamental para o letramento intercultural dos(as) docentes e para uma aproximação com a causa indígena.
\end{abstract}

PALAVRAS-CHAVE: Kaingang, Povos Originários, Licenciatura Intercultural Indígena.

ABSTRACT: The present article wants to show the challenges and advances that occurred during the formation process in the intercultural indigenous degree in the course of Mathematics and Natural Sciences in a community university in the south of Brazil with emphasis on the formation in Sciences and Biology. The methodology included bibliographic research, document analysis and interviews. The need to understand the trajectory of indigenous peoples in the social historical process was a guide to understand contemporary history that led to the need for a differentiated indigenous education in Brazil. The Unochapecó Indigenous Intercultural Degree meets this historical need and to better understand how this path took place, we interviewed three teachers who worked during the training process in this modality, in order to give visibility to the nuances of working with teacher training in indigenous lands. During the interviews, the great effort of the interviewees to promote intercultural practices was evident, however, the lack of initial training was reflected in the discourse that still carries some colonial aspects. During the

\footnotetext{
${ }^{1}$ Mestrando em Educação pela Universidade Comunitária da Região de Chapecó - Unochapecó. Bolsista Integral CAPES. Membro do Grupo de Pesquisa SULEAR. E-mail: bernard.dariva@gmail.com

2 Doutora em Educação pela Universidade Federal de Pelotas - UFPel. Professora da Universidade Comunitária da Região de Chapecó - Unochapecó. E-mail: battestin@unochapeco.edu.br
} 
Espaço Ameríndio

training process, awareness of the theme was fundamental for the intercultural literacy of the teachers and approach to the indigenous cause.

KEYWORDS: Kaingang, Original Towns, Intercultural Indigenous Degree. 
Espaço Ameríndio

\section{Introdução}

A partir da chegada dos primeiros "conquistadores", os povos originários da América vivenciaram um dos mais violentos processos de dominação e exploração da humanidade (SOLANO-ALPíZAR, 2015). Fundamentado em valores de uma suposta racionalidade universal e superioridade étnica, a imposição de um único movimento civilizatório através do domínio, visava a subordinação e o apagamento de toda cultura não europeia. O projeto colonial repudiava qualquer possibilidade de manifestação ou expressão de crenças, ritos e cosmologia das inúmeras etnias milenares autóctones. Com isso, os mecanismos de controle e exploração estiveram presentes em todos os campos da existência humana, produzindo ao longo de cinco séculos marcas profundas que modificaram e marginalizaram as culturas originárias. Esta é uma luta constante pela valorização e reconhecimento ao acesso no ensino superior e, também, por uma educação diferenciada que dialogue com as necessidades de cada etnia e região.

Desde o Brasil colônia até meados do século XX, a educação indígena foi inexistente no Brasil. A relação entre Estado e os povos originários, historicamente, tendenciou à integração e homogeneização cultural. Somente no final do século $X X$, diante da articulação da sociedade civil e dos povos originários, foram discutidos e criados documentos que contemplam as necessidades de uma educação indígena contextualizada. Estas propostas foram desdobradas e consolidadas na constituição de 1988 com a criação da nova Lei de Diretrizes e Bases da Educação Nacional (LDB). Assim, como desdobramento, foi elaborado o Referencial Curricular Nacional para as Escolas Indígenas (RCNEI), uma nova proposta curricular que busca atender os interesses políticos e pedagógicos dos povos indígenas (BRASIL, 1998).

De acordo com o último censo, o número de pessoas que se auto declararam indígenas no Brasil chegou a aproximadamente 896 mil. Em Santa Catarina, são cerca de 18.213 e destes, aproximadamente 10.000 vivem na região oeste (IBGE, 2010). No ano de 2020, em conversa com lideranças Kaingang, foram estimadas cerca de 30 mil em SC. Diante desta diversidade histórica, e na busca por atender à legislação e ofertar uma educação indígena contextualizada, a Universidade Comunitária da Região de Chapecó (Unochapecó), em convênio com a Secretaria Estadual de Educação de Santa Catarina (SEDSC), iniciou no ano de 2009 a formação superior em Licenciatura Intercultural Indígena. Ofertado no Oeste de Santa Catarina, esta foi a primeira experiência realizada quase que integralmente em terras indígenas (UNOCHAPECÓ, 2009). É com este desejo e desafio que a Unochapecó segue formando estudantes indígenas há mais de 11 anos, sendo referencial em formação de professores no Sul do Brasil, principalmente pelo fato de levar a universidade até as comunidades indígenas.

Para o desenvolvimento desta pesquisa, utilizamos como métodos a pesquisa bibliográfica, análise documental e entrevistas. Desta forma, a fim de conhecer quais foram as necessidades que levaram à criação de uma formação indígena diferenciada, buscamos na primeira sessão 
contextualizar os processos histórico-sociais vivenciados pelos povos indígenas durante a conquista e colonização do Brasil. Na segunda sessão, intentamos compreender a trajetória contemporânea da educação indígena no Brasil. Na terceira sessão, direcionamos os esforços na tentativa de identificar sob quais aspectos metodológicos e sociais o curso de Licenciatura Intercultural Indígena da Unochapecó foi construído. Por fim, na quarta sessão, estreitamos o diálogo com os(as) docentes que atuaram no curso através de entrevistas com o objetivo de entender os diversos aspectos que perpassaram o processo de construção do curso e formação de professores indígenas nesta modalidade.

\section{A marca da ferida colonial nos povos originários do brasil: uma breve contextualização}

Antes de tecer reflexões a respeito de uma temática, é necessário buscar as raízes deste problema, ou seja, contextualizar a historicidade a fim de compreender os motivos pelos quais o assunto pesquisado se encontra em seu momento atual. Desta forma, a conjuntura histórica da nossa investigação será contada a partir do momento em que os primeiros conquistadores chegaram em terras brasileiras. Assim, nesta parte da escrita, buscamos elucidar o contexto histórico que levou as populações originárias do Brasil a uma vivencia de exclusão e marginalização social.

É importante partir da compreensão de que as terras recém encontradas, que foram chamadas de o Novo Mundo e posteriormente de América, fizeram e ainda fazem parte de um projeto de conquista. Conforme a argumentação de Mignolo (2017, p. 4), a América não era uma entidade a ser descoberta, foi inventada. Sendo assim, entendemos que, tal como a América, o Brasil já era colonizado pelos povos originários há milhares de anos. Diante disto, iremos assumir durante a escrita a categoria de conquista para tratar do processo colonizatório imposto no Brasil.

Para avançar na discussão, é necessário termos a compreensão de o porquê a América foi primeiramente chamada de o "Novo Mundo". De acordo com a perspectiva eurocêntrica, o período histórico da conquista seria conhecido posteriormente como sendo a Modernidade, devido a algumas mudanças sociais, culturais e tecnológicas ocorridas nas relações humanas. Neste sentido, justamente para a razão moderna, o novo seria a representação de imaturidade, algo ainda em processo de ser. Com isso, a América não poderia ser parte do mundo já existente, já que para o conquistador, não havia história antes de sua chegada. Para Dussel, seria então [...] "A "imaturidade" total, física, (até os vegetais e os animais são mais primitivos, brutais, monstruosos; ou simplesmente mais fracos, degenerados) é o signo da América (Latina)" (1993, p. 17). Desta forma, as populações humanas pré-conquista na América foram relegadas à pré-história.

Ao chegarem no que viria a ser o Brasil, os conquistadores europeus se depararam com vasta diversidade de povos nativos. Em 
muitos casos, estes povos viviam sem estruturas de classes e eram unidos por laços de sangue. De acordo com Saviani (2013), os povos préconquista tinham maneiras particulares de organização social, educação e cultura. Era comum a prática de um sistema de educação integral, em que cada membro aprendia o que fosse possível dentro das relações sociais. Os povos originários do Brasil representavam culturas milenares, portanto, haviam desenvolvido sistemas de organização social complexos ao longo de gerações. Dentre as diversas etnias de povos originários, não havia uma específica organização social que pudesse ser reconhecida pelo conquistador, em seus sistemas não tinham terras privadas, não havia um comércio baseado em uma única moeda, não havia um sistema de leis complexos, venda e compra de produtos, e ainda, as práticas religiosas não eram cristãs. Assim, ao não reconhecer, de acordo com a perspectiva eurocêntrica, na organização social dos povos nativos categorias humanas, os conquistadores de deslocam todo outro à uma categoria de inferioridade (QUIJANO, 2000).

Aprofundando a discussão, antes de avançarmos na contextualização histórica, é salutar compreender como surge esta noção que coloca o não europeu em uma categoria de inferioridade. Para Dussel (1993), temos que a razão moderna parte da compreensão de que a Europa é a última etapa da civilização humana, a partir de um processo natural do desenvolvimento. Nesta perspectiva, a cultura europeia é entendida como complexa e desenvolvida, enquanto o não-europeu é primitivo e, portanto, parte do passado da humanidade.

A ideia de superioridade natural foi sobremaneira importante no processo de imposição violenta da conquista. Neste sentido, Quijano (2000) argumenta que a suposta superioridade natural se reconfigurou diante da ideia de raça, que se origina na relação entre conquistadores e conquistados e inaugura uma nova relação de poder que leva em conta as diferenças fenotípicas e culturais. Esta categoria cria novas identidades: índios, negros, brancos, mulatos, caboclos, mestiços e etc. Como codificação emblemática à ideia de raça, os conquistadores assumiram para si a categoria de brancos como raça superior em relação às demais. A racialização como forma de classificação social se estabelece através das colônias europeias e se mundializa. Para o referido autor, esta será a base estrutural para o modelo de mundo moderno que surge e se constitui de maneira hegemônica.

Diante da ideia de raça como categoria de inferioridade do não europeu, o projeto de conquista pôde atuar em todas as esferas da vida humana. A persuasão religiosa talvez tenha sido a primeira ferramenta da conquista europeia e esteve presente desde o início do processo colonizatório. Desta forma, desde o início da conquista estiveram presentes as ordens missionárias, sobretudo, com atuação mais expressiva, jesuítas e franciscanos. Se o discurso religioso destas ordens era supostamente o de "salvar" e "arrebanhar" novas almas, sua presença era uma importante ferramenta de dominação das populações nativas. Com isso, foi necessário a criação de argumentos que tornassem válidos os processos de domínio a partir de um discurso filosófico de superioridade natural. Para isso, utilizaram-se fundamentos aristotélicos 
da servidão por natureza. Este pensamento partia da interpretação de que bárbaros são naturalmente escravos (GUTIÉRREZ, 2014). Os povos nativos eram considerados bárbaros por não ter em sua estrutura social e racional nenhuma categoria reconhecida pelo europeu. Assim, se os povos nativos seriam bárbaros, estaria justificado a imposição civilizatória eurocentrada, para que assim fossem libertados de sua suposta condição de barbárie (DUSSEL, 1993).

De acordo com Melatti (1977), é possível dividir os trabalhos missionários em duas fases. Na primeira, por acreditarem que a conversão seria fácil, as tentativas de conversão ao cristianismo ocorriam de maneira itinerante. Contudo, ao perceberem que as populações nativas não demonstravam entender de fato os significados das práticas cristãs, missões fixas foram estabelecidas. Aglomerados em espaços confinados em regime de internato, nas missões fixas os indígenas eram parcialmente letrados em português, aprendiam a rezar e cantar em latim e, em alguns casos, praticavam agricultura. Estas práticas estavam fundamentadas pela percepção de que o "índio"3 era como uma folha em branco em que se poderia introduzir os valores e práticas cristãs (DE ALMEIDA, 2016; MELATTI, 1977).

A presença do europeu foi responsável pela disseminação de diversos patógenos entre os povos nativos, principalmente tuberculose e varíola. Por se tratar do primeiro contato com estas doenças, os sintomas eram muito mais graves nas populações indígenas com relação aos europeus, que já haviam desenvolvido imunidade a estes agentes. Ainda, o contágio era facilitado pela mudança na estrutura social à qual os povos nativos eram submetidos, sobretudo pelas grandes aglomerações das missões. Sem o conhecimento da existência destas doenças, ao observarem o crescente número de mortes sem um motivo aparente, os padres acreditavam que as causas seriam decorrentes da falta de fé dos "índios", sendo, portanto, um castigo de Deus (MOONEN, 2008; NETO; MACIEL, 2008).

Se o contato com novas doenças foi responsável por exterminar populações inteiras de povos nativos, para Quijano (2000), o trabalho escravo foi ainda mais devastador. Durante o período colonial, a escravidão indígena foi, por diversas vezes, permitida e proibida, a depender dos interesses dos conquistadores. No começo, os indígenas eram, sobretudo, parceiros comerciais dos europeus, trocando recursos naturais, como, por exemplo, o pau-brasil por ferramentas. Durante a instalação da Colônia portuguesa, esta relação se alterou, uma vez que os conquistadores não desejavam mais parceiros para escambo, mas sim, mão de obra e força militar para os processos coloniais. Nas missões, os povos indígenas não eram escravizados e estavam sob a tutela dos padres, que eram contrários à prática. Segundo Melatti (1977), embora fossem contrários à escravidão, os missionários eram favoráveis ao aldeamento forçado. Fora das missões, enquanto brancos recebiam

\footnotetext{
${ }^{3}$ Os conquistadores chamavam (de forma errônea) os nativos de "índios" porque acreditavam ter chegado nas Índias Orientais.
} 
salários, indígenas e negros eram forçados a trabalhar em regime de escravidão até a exaustão e, comumente, até a morte.

As relações de disputas entre as populações nativas sempre existiram, mas os conflitos estabelecidos com a chegada dos conquistadores instauraram uma nova forma de poder diante do genocídio. Utilizando as relações históricas de hostilidade entre povos rivais, os conquistadores promoveram expedições de guerra visando ganhos com o extermínio de povos mais irredutíveis à dominação (DA CUNHA, 2013). Portanto, etnias mais próximas dos conquistadores recebiam armamentos em troca de auxilio nas campanhas de extermínio e captura de indígenas pertencentes a grupos rivais. Diante disto, uma rede especializada no comércio de escravos indígenas se estabelece. Fugindo do avanço dos conquistadores, populações indígenas migravam para áreas além de sua territorialidade. Deixar o território milenar pode ser percebido como uma atitude drástica, um último recurso, já que ao deslocarem-se de suas áreas milenares e cosmológicas, colocavam sua própria existência em risco (DA CUNHA, 2002).

Cabe ressaltar que o processo de conquista não ocorreu sem que houvesse resistência dos povos indígenas. Enquanto algumas populações se mostraram mais amistosas, como os Carijós do litoral sul do país, chamados pelos portugueses de "o melhor gentio da costa", outros foram irredutíveis ao avanço dos conquistadores. Temos o registro histórico de diversas formas de resistência, sejam pelas fugas das missões, das incursões de guerra, ataques a fazendas e engenhos, ou, em casos mais extremos, o suicídio daqueles feitos prisioneiros ou escravos. Ao remontar a historicidade da luta dos povos indígenas, Vainfas (1995) recorda que em resposta às práticas realizadas pelos conquistadores, algumas etnias indígenas se uniram, como foi o caso da Confederação dos Tamoios e a Confederação dos Kairiris - contudo, diante do vasto poder militar das Coroas, estes levantes foram suprimidos em dado momento.

Apesar do projeto de conquista ter por fundamentação a prática violenta de dominação e subalternização do outro a partir da categoria racial, evidencia-se a necessidade de garantir a Colônia politicamente. Com isso, mais de dois séculos após a chegada dos primeiros conquistadores, reformas nas políticas indigenistas foram promovidas. Neste momento, houve clara separação entre Estado e igreja. Entre outras pautas, as reformas pretendiam abolir a escravidão de nativos e expulsar os jesuítas da vida social nas Colônias. Sobretudo, o maior interesse com o fim da escravidão indígena era o de integrá-los à sociedade colonial e formar fronteiras vivas, já que, em substituição ao Tratado de Tordesilhas, o de Madrid previa que as fronteiras sul-americanas entre Portugal e Espanha seriam formadas de acordo com o idioma falado. Para tanto, eram incentivadas a miscigenação entre indígenas e brancos, em uma tentativa de homogeneizar e "europeizar" a população brasileira. Do mesmo modo, o idioma guarani foi proibido e surgiram escolas indígenas para o letramento em português (GARCIA, 2007; SECO, 2006). Diante desta perspectiva, não é difícil notar que em nenhum momento a liberdade de ser dos povos indígenas foi respeitada: pelo contrário, todas 
as ações coloniais estavam diretamente relacionadas aos interesses do projeto de conquista.

Este breve relato dos processos de conquista intentou desvelar minimamente as marcas históricas provocadas nos povos originários do Brasil, cuja cultura e valores foram e seguem sendo desconsiderados há mais de cinco séculos. A conquista ocorreu através de um projeto que inferiorizou outras formas de ser através da racialização, criando estruturas de controle e poder que impediram a existência do outro. Recordando Galeano (2018), as veias da América seguem abertas. Assim, igualmente, as feridas coloniais seguem expostas, sobretudo, na vida dos povos indígenas do Brasil.

Em seguida, iremos tratar brevemente do processo tardio, mas não menos violento, de conquista da região sul do Brasil, cujas marcas são ainda mais recentes nas etnias autóctones.

\section{Marcas recentes: a conquista tardia no sul do Brasil}

O processo de conquista e expansão colonial na região sul do Brasil foi tardio. Ainda que iniciado no século XVI - sobretudo pela ação dos jesuítas que já haviam estabelecido a missão de Guaíra, por exemplo (D'ANGELIS, 2014) -, foi somente do século XVIII ao final do XIX que o avanço dos conquistadores sobre o território indígena foi intensificado. De acordo com Carbonera (2011), existem registros da ocupação de diversas etnias indígenas nas áreas que hoje compreendem os Estados do Paraná, Santa Catarina e Rio Grande do Sul há pelo menos 12 mil anos. Dentre as etnias, as principais são parte do grupo linguístico Tupi, que deu origem aos Guarani, e do grupo linguístico Jê, dando origem aos Kaingang e Xokleng.

A etnia Kaingang historicamente foi mais irredutível às reduções jesuíticas, ainda que alguns registros históricos indiquem casos específicos nos quais alguns grupos Kaingang teriam sido influenciados pelos jesuítas (VEICA, 2000). Com isso, limitavam sua distribuição a zonas de campo e Floresta de Araucária (D’ANGELIS, 2014), longe do avanço colonial. Com a destruição das missões jesuítas no início do século XVII e o avanço das expedições bandeirantes, os povos Kaingang se dispersaram, fragmentando seu território por toda região sul, desde os Estados do Rio Grande do Sul até São Paulo.

Diante do exposto, se anteriormente ao século XVIII não havia interesse econômico na ocupação da região sul, da sua metade em diante diversas campanhas militares são empregadas com o objetivo de reconhecer e tomar posse dos territórios ocupados pelos povos nativos livres e que ofereciam resistência aos avanços das expedições. Escravizar os povos indígenas não era mais o objetivo, mas sim, conquistar suas terras para explorar recursos naturais, implantar monoculturas e estabelecer comunidades. Apesar da reação dos povos Kaingang em oferecer forte resistência, as expedições militares não cessaram: ao todo foram onze entre os anos de 1768 e 1774. Como estratégia de conquista, frequentemente lideranças indígenas de grupos aliados aos brancos 
recebiam patentes militares e um pago em salário, e assim, ajudavam na localização e conquista dos últimos povos Kaingang livres do sul do Brasil (SANTOS, 2018; VEIGA, 1994).

Já no século XIX, ao mesmo passo que a expansão das monoculturas, linhas ferroviárias e privatização de terras seguiam desapropriando territórios indígenas através da ação de companhias colonizadoras. Muitos aldeamentos foram criados com o objetivo de redirecionar as populações indígenas que eram forçadas a abandonar seus territórios. A pressão das expedições da conquista forçava, cada vez mais, a dispersão de grupos Kaingang livres remanescentes, até que fossem novamente localizados e coagidos ao aldeamento forçado. Conforme relatado por D'Angelis (2014), o massacre aos povos indígenas fazia parte de um projeto com atuação em todas as esferas sociais. $O$ referido autor relata, ainda, a atuação dos chamados "bugreiros" no oeste de Santa Catarina, que seriam pessoas da população civil incumbidos de caçar e assassinar indígenas ainda não aldeados, e por isso recebiam quantias em dinheiro ao comprovarem as mortes através da exposição de cabeças, escalpos ou outras partes dos corpos. Com isso, além de um projeto de conquista violenta, fica evidenciado que as populações originárias foram submetidas a um projeto de "limpeza étnica", cujo objetivo era o de apagar toda uma cultura milenar da história.

Mesmo com as fortes investidas do Estado, os povos Kaingang ofereceram forte resistência, atacando pequenos povoados, fazendas, destruindo construções e através de embates com os militares. Apesar da sangrenta resistência dos Kaingang, no século XIX os últimos territórios livres do Sul são conquistados, com algumas exceções nos Estados de São Paulo e Paraná. Foi somente com a criação do Serviço de Proteção ao Índio (SPI) e da Fundação Nacional do índio (FUNAI) no final do século XX que esta situação foi amenizada e as terras indígenas foram parcialmente estabelecidas (VEIGA, 1994).

Devido à trajetória vista até aqui, foi evidenciado que os povos indígenas sofreram um longo processo de exclusão, exploração e desapropriação territorial, sem ter direito de acesso às políticas públicas e de inclusão social. Este processo de segregação, que dura mais de meio milênio, impôs aos povos indígenas do Brasil um único movimento civilizatório que alterou profundamente a dinâmica sociocultural em torno das quais viviam. Neste sentido, são necessárias iniciativas que priorizem a retomada da autonomia, proporcionem a valorização cultural e inclusão social aos povos indígenas. Assim, na seção seguinte iremos abordar a trajetória da educação indígena no Brasil a partir do século XX, que surge como uma necessidade histórica diante do processo de conquista.

\section{A trajetória da educação indígena no brasil}

Conforme mencionamos anteriormente, desde o período colonial as políticas públicas de educação não foram pensadas para os povos indígenas. Por mais de cinco séculos, as propostas educativas estiveram 
articuladas com o projeto da conquista, que consistia em promover a assimilação e homogeneização das culturas originárias. Esta tendência integracionista se manteve na política indigenista brasileira até o final do século XX.

O Estado jamais houvera pensado em uma educação diferenciada para os povos originários. As línguas indígenas eram consideradas inferiores e o ensino seguia a lógica de um currículo fechado, com conteúdo específico em língua portuguesa. A partir da década de 1970, alguns setores da população exercem pressão para a criação de entidades de apoio aos povos indígenas. As comunidades indígenas passaram a se organizar em oposição às ações integracionistas do Estado. Estes movimentos ganharam visibilidade com as grandes reuniões organizadas pela União das Nações Indígenas (UNI) (BRASIL, 1998).

Em decorrência da mobilização social, movimentos como o dos "Encontros de Professores Indígenas", nos quais eram discutidas questões referentes a uma educação intercultural pautada nas necessidades de cada etnia, foram intensificados. Diante destes encontros, foram produzidos documentos em que as reivindicações de uma educação indígena diferenciada estão expressas por povo, estado, região e etnia. Estes documentos estabelecem críticas ao modelo escolar para educação indígena até então vigente (GRUPIONI, 2002).

Durante o ano de 1988, movimentos indígenas intensificaram as ações e articularam-se juntamente ao poder público, participando de reuniões parlamentares, discutindo a temática indígena e conduzindo iniciativas para objetificar seus direitos. Estas mobilizações foram fundamentais para consagrar os direitos indígenas na futura Constituição do Brasil e impedir ações de segmentos contrários interessados na exploração de seus territórios. Com isso, a Constituição da República Federativa do Brasil foi promulgada em outubro de 1988 e estabelece direitos e deveres dos indivíduos que compõem o Estado, e necessita, por excelência, atender as necessidades da nação pela qual está em vigor (BRASIL, 1998).

A legislação anterior à Constituição de 1988 orientava para a assimilação dos povos indígenas, já que as leis nacionais tratavam todos os brasileiros como iguais em uma perspectiva étnica, cultural e linguística (GRUPIONI, 2002). Entretanto, a nova constituição reconhece os povos indígenas como detentores do direito de exercer suas expressões étnicas e socioculturais. O Título VII "Da Ordem Social" capítulo VII denominado "Dos índios", afirma que: "São reconhecidos aos índios a sua organização social, costumes, línguas, crenças e tradições, e os direitos originários sobre as terras que tradicionalmente ocupam, competindo à União demarcá-las, proteger e fazer respeitar todos os seus bens" (BRASIL, 1998, p. 31).

A maior conquista da Constituição de 1988 foi o rompimento, ainda que legislativo, da tradição integracionista e de assimilação dos povos indígenas. Desta forma, o Estado não deve apenas garantir a existência das populações indígenas, mas, sim, promover a reafirmação e valorização de suas culturas e línguas maternas. A Constituição garante o uso de processos próprios de aprendizagem. Assim, abriu-se a 
possibilidade para que as escolas indígenas valorizassem seus saberes e tradições, deixando de se submeter aos valores da cultura da sociedade não indígena (BRASIL, 1998).

Como desdobramentos da Constituição, temos a criação de importantes documentos que regulamentam a política de educação, como a Lei e Diretrizes de Bases da Educação Brasileira - LDB, n 9394/96, os Parâmetros Curriculares Nacionais - PCNs, Plano Nacional de Educação PNE e o Referencial Curricular Nacional para Escolas Indígenas - RCNEI, de 1998. Estes documentos representam um grande avanço nas políticas de inclusão e respeito às diferenças culturais dos povos indígenas na perspectiva legislativa. Contudo, devem ser aplicados em ações que garantam suas proposições.

Com isso, após este breve recorrido sobre as lutas e direitos garantidos pelos povos indígenas de uma educação contextualizada e diferenciada, na seção seguinte iremos compreender o processo de criação do curso de Formação de Professores na Licenciatura Intercultural Indígena da Unochapecó.

\section{A Licenciatura Intercultural Indígena da Unochapecó}

$\mathrm{Na}$ busca por atender as demandas no âmbito legislativo de uma educação contextualizada e diferenciada para os povos originários do Brasil, é criado no ano de 2009 a primeira experiência de Licenciatura Intercultural Indígena no oeste de Santa Catarina. Ofertado pela Unochapecó em parceria com a Secretaria Estadual de Educação do Estado de Santa Catarina, esta foi a primeira experiência de formação intercultural do sul do Brasil desenvolvida quase que integralmente em terras indígenas. As aulas ocorreram e ocorrem tanto na universidade quanto no interior das terras indígenas. Já foram atendidas as Terras Indígenas Xapecó, Toldo Chimbangue, Toldo Pinhal, Toldo Imbu e Terra Indígena Kondá, localizadas nos municípios de Ipuaçu, Entre Rios, Abelardo Luz, Chapecó e Seara, todas cidades do Oeste do Estado de Santa Catarina. A formação contempla quatro áreas do conhecimento: a) Matemática e Ciências da Natureza; b) Ciências Sociais; c) Línguas, Artes e Literaturas; e d) Pedagogia (UNOCHAPECÓ, 2009).

O Projeto Político Pedagógico (PPC) do curso prevê a formação conforme as Diretrizes Curriculares Nacionais destinadas à Educação Escolar Indígena e do RCNEI, que pretende uma educação escolar contextualizada, intercultural, bilíngue e que atenda às necessidades das comunidades indígenas (UNOCHAPECÓ, 2009). Com isso, a proposição do curso é a de formar professores para atuarem na educação escolar indígena, contribuindo para o avanço das suas comunidades, na valorização, fortalecimento de sua cultura e valores étnicos.

Os processos pedagógicos do curso foram construídos com professores, estudantes, lideranças, membros das comunidades indígenas e representantes de entidades regionais como a FUNAI, Secretarias Municipais e Estadual de educação, Conselho Indigenista Missionário (CIMI) e Áreas Acadêmicas da Unochapecó. As bases 
curriculares do curso foram construídas a partir de outras experiências de licenciaturas interculturais no Brasil (UNOCHAPECÓ, 2009).

A área de Matemática e Ciências da Natureza visa a formação de professores de Matemática e Ciências para o ensino fundamental e Biologia, Física, Matemática e Química para o ensino médio. Tratando especificamente do ensino de Ciências e Biologia, o texto que direciona a construção desta área preconiza o seu potencial na aplicação de uma pedagogia intercultural, seguindo o entendimento de que todas as sociedades mantêm uma forte relação de interdependência com a natureza, orientando para a resolução de problemas que atendam as demandas reais do cotidiano. O programa do curso prevê uma abordagem não estática, por entender que a dinâmica social está em constante transformação e necessita de intervenção dos membros que a compõem. Assim, as discussões devem ser direcionadas para a compreensão e debate entre as diferentes formas utilizadas pela comunidade indígena e não-indígena de existir (UNOCHAPECÓ, 2009).

É perceptível que o eixo do programa foi construído a partir de um processo que articulou diversos setores da sociedade civil e comunidade acadêmica em busca de ofertar uma educação intercultural que atenda às demandas das comunidades indígenas às quais o curso se destina. Entretanto, além das bases teóricas, é necessário entender como o processo formativo se desenvolve na prática. Identificar todos os aspectos que perpassam esta trajetória é fundamental ao desenvolvimento de novas estratégias que busquem sanar possíveis fragilidades, assim como potencializar aspectos positivos. É nesta ampla gama de possibilidades em poder trabalhar a interculturalidade na licenciatura que buscamos dialogar com os professores que trabalharam na formação dos estudantes indígenas em Ciências e Biologia.

\section{A licenciatura intercultural indígena: nuances do processo formativo}

Entendemos que estreitar o diálogo com os(as) professores(as) diretamente envolvidos (as) no processo de formação intercultural é uma ferramenta de grande importância para construir caminhos de reflexão. Assim, através de entrevistas, dialogamos com três docentes que compuseram o quadro do curso de Matemática e Ciências da Natureza na formação em Ciências e Biologia.

É importante salientar que o intuito inicial da pesquisa realizada entre o ano de 2019 e meados de 2020 era o de dar voz também aos estudantes indígenas que participaram deste processo, para que assim pudéssemos compreender os percalços e contribuições desta trajetória a partir de outras perspectivas. Contudo, em respeito às medidas sanitárias frente às adversidades impostas decorrentes da pandemia de Covid-19 (SARS COV-2), e, ainda, pelos aspectos éticos de uma pesquisa envolvendo povos indígenas, optamos pela não realização desta abordagem metodológica com os egressos do curso. Ressaltamos ainda que as entrevistas com os(as) docentes foram realizadas ao final do ano de 2019 - portanto, anteriormente ao cenário de pandemia atual. 
Intentando sistematizar um panorama da concepção dos professores referente ao processo de formação, optamos por desenvolver as perguntas a partir quatro categorias gerais: preparo para a docência intercultural; práticas pedagógicas interculturais; dificuldades e alternativas construídas; contribuição da formação intercultural indígena. Desta forma, esperamos compreender um pouco mais sobre as nuances deste processo de formação a partir das experiências dos(as) docentes.

Nas seções subsequentes, os(as) professores(as) entrevistados(as) serão representados(as) pelas letras "A", "B" e "C", para que suas identidades sejam mantidas preservadas de acordo com os critérios éticos desta pesquisa.

\section{Preparo para a docência intercultural}

Para iniciarmos o diálogo com os(as) docentes entrevistados(as), consideramos oportuno perguntar se os(as) professores(as) se sentiram preparados(as) para trabalhar na formação em Ciências e Biologia da Licenciatura Intercultural Indígena.

As respostas foram unânimes, evidenciando que faltou formação e capacitação sobre o contexto intercultural oferecido na proposta desta modalidade. Igualmente, muitos conhecimentos foram adquiridos no decorrer do processo com a vivência prática e teórica. Referente a esse questionamento, o(a) professor(a) "A" fez o seguinte comentário:

[...] Quando fui convidado(a) a fazer parte do curso como docente eu não tinha profundidade no conhecimento sobre as questões indígenas, eu só fui perceber a importância de uma preparação já dentro do curso. A preparação à qual eu me refiro é o fato de que a educação indígena é diferenciada. Então, é importante conhecer a legislação das políticas educacionais. Tudo isso era um universo novo que se apresentava para mim.

Do mesmo modo, o(a) professor(a) "B" também direciona sua resposta nesta perspectiva, recordando que:

[...] Na verdade não tivemos capacitação. Justamente por ser a primeira experiência do curso, os professores foram se inserindo e dando conta dos conteúdos e ao mesmo tempo tendo que buscar referências na bibliografia no que diz respeito a interculturalidade indígena.

O(a) professor(a) "C" também observa que o processo inicial foi desafiador:

[...] Em nenhum momento recebemos capacitação para trabalhar a interculturalidade. O que fizemos, por iniciativa própria, foi tentar buscar as referências 
indígenas de forma coletiva ou em outros trabalhos e experiências de outros cursos, mas não tivemos capacitação inicial para fundamentar nosso trabalho.

A partir destes relatos inicias é pertinente observar o quanto foi desafiador para os(as) professores(as) que trabalharam nesta modalidade, não somente pelo aspecto de interculturalidade, mas principalmente por ser um curso pioneiro na região e no Estado de Santa Catarina, ao ofertar uma experiência quase que integralmente desenvolvida em terras indígenas. O importante foi observar que os professores perceberam e buscaram conhecer mais sobre a cultura indígena da comunidade na qual as aulas eram ministradas e a perspectiva intercultural durante este processo.

\section{Práticas pedagógicas interculturais}

Ao perguntarmos para os(as) professores(as) sobre quais práticas pedagógicas interculturais foram desenvolvidas a partir das aulas, obtivemos respostas similares. Assim como o preparo para a docência intercultural apresentou fragilidades, as práticas pedagógicas interculturais também apresentam considerações a serem pensadas. O(a) professor(a) "B" salienta que:

[...] Este foi um grande desafio, por mais que tivéssemos outros modelos de experiências de base teórica, a realidade era outra. Em cada comunidade as turmas tinham particularidades, então as práticas pedagógicas eram pensadas a partir do diálogo com os estudantes, pensar propostas para atender a realidade de cada um.

Os(as) professores(as) "B" e "C", também sinalizaram como o ambiente externo da sala de aula era útil para compreender e conhecer a realidade das comunidades, já que as aulas eram realizadas nas escolas dentro destes territórios:

[...] Uma das práticas desenvolvidas era sair do ambiente de sala de aula e entender quais os problemas ambientais da comunidade indígena (Professor(a) B).

[...] Eu busquei, por exemplo, na educação ambiental, trabalhar com o estudo do meio e conhecer o entorno de onde eles vivem, como cuidam, como é o manejo e qual a visão da comunidade sobre isso. Também trabalhamos aspectos relacionados aos hábitos alimentares da cultura Kaingang. Todas as atividades foram desenvolvidas buscando atender as diretrizes do RCNE (Professor(a) C). 
É possível observar o quanto os(as) professores(as) fizeram uso do espaço externo da escola em uma tentativa de promover um ensino contextualizado, trabalhando a partir da realidade do entorno, estreitando o diálogo com os seus membros.

Nesta perspectiva, a(a) professor(a) "B", sinaliza:

[...] Uma das práticas foi a de conhecer aspectos de sua própria cultura no passado. Eles foram instigados a perguntar para os membros das comunidades e anciãos sobre como eram os hábitos no passado e relacioná-los com o presente.

É notório o esforço de interculturalidade dos(as) docentes em buscar alternativas de aproximação com outras realidades em espaços diversificados. Por exemplo, o(a) professor(a) "B" levou os estudantes para a Universidade, desenvolvendo práticas que somente são possíveis com a estrutura do laboratório de biologia:

[...] Foram realizadas aulas práticas nos laboratórios da Unochapecó para que eles tivessem também a vivência acadêmica dentro da universidade. Do mesmo modo, diversos materiais foram levados da universidade para as comunidades, como por exemplo, espécimes da coleção científica do Museu de Ciências Naturais da Universidade, além de buscar a observação na própria comunidade para identificar a biodiversidade destes locais.

Essas práticas pedagógicas mostram o quanto é necessária e importante uma estrutura física e laboratorial na formação em Ciências e Biologia. Percebemos também a fragilidade imposta frente à falta de conhecimento sobre a cultura e realidade dos estudantes, o que poderia tornar a prática intercultural muito mais objetiva, sem que houvesse necessidade de grandes adaptações no decorrer do processo. Em qualquer modalidade de ensino é um desafio pensar em práticas pedagógicas. Contudo, quando se trata de um espaço praticamente desconhecido, com uma cultura específica e diferenciada, os desafios tornam-se ainda maiores. Assim, destacamos o esforço e a coragem dos(as) docentes em adaptar práticas interculturais à formação já em andamento.

\section{Dificuldades e alternativas construídas}

Durantes a trajetória vista até então, ficou evidente que a construção metodológica se deu ao longo do curso. Os desafios foram muitos e nesta perspectiva perguntamos aos(as) professores(as) se: haviam elementos pedagógicos suficientes para trabalhar a interculturalidade? Diante deste questionamento, o(a) professor(a) "A" relata que: 
[...] Logo no início percebemos essa fragilidade de elementos didáticos pedagógicos na escola. Por esse motivo, os alunos foram trazidos para a universidade, tendo em vista as melhores condições do espaço físico.

Por se tratar da primeira experiência e ainda pela falta de capacitação por parte dos(as) docentes, as carências didáticopedagógicas precisaram ser contornadas. Mediante isto, o(a) professor(a) "C" recorda:

[...] Sim, havia carências e nos deparamos com a falta de materiais didáticos para trabalhar nos cursos, sejam livros ou modelos. A proposta do curso sempre foi a de produzir materiais didáticos para atender as especificidades dos alunos. Com isso, utilizamos alguns modelos do que já foi trabalhado em outras experiências não interculturais e adaptamos para a realidade de cada turma. Além disso, buscamos por conta própria material e bibliografia

Durante 0 processo de formação, os(as) professores(as) observaram o quanto os estudantes demonstravam habilidades manuais na produção de artesanatos. Percebendo esta facilidade, os(as) professores(as) trabalharam com modelos didáticos produzidos pelos próprios alunos. Neste sentido, o(a) professor(a) "B" relembra que:

[...] Das práticas que me recordo percebemos que os alunos tinham boa desenvoltura de habilidades manuais. Então, planejamos sempre que possível este tipo de atividade, como desenhar estruturas de plantas, árvores e o corpo humano, tudo com materiais alternativos recolhidos do meio ambiente. Com a alternativa pedagógica foi feito também um levantamento sobre as plantas medicinais que utilizavam e sua função, em que os alunos deveriam perguntar aos membros mais velhos sobre como este conhecimento era no passado.

É importante observar que, apesar das dificuldades, as alternativas construídas viabilizaram um ensino integrado com a comunidade indígena. O espaço físico e a estrutura de acesso à internet das comunidades também foram barreiras durante a formação, conforme os(as) professores(as) "A" e "B" sinalizam:

[...] O espaço físico das salas não possuía uma estrutura de rede adequada e o acesso tecnológico era deficitário. Neste sentido, foram levados projetores e computadores da universidade para as aulas expositivas (Professor(a) B).

[...] Levávamos também textos impressos, já que a maior parte não tinha acesso à internet. Também eram 
levados projetores e notebooks para trabalhar elementos que não faziam parte do cotidiano dos alunos (Professor(a) A).

É perceptível que houve diversas fragilidades ao longo do processo de formação do curso e que tiveram de ser contornadas. Contudo, os(as) professores(as) tiveram êxito parcial na tentativa de compreender a realidade dos alunos, propondo alternativas para a promoção de um ensino intercultural frente às dificuldades impostas.

Compreendemos que para trabalhar com uma formação diferenciada e que atenda às demandas dos povos indígenas é preciso ir além de um planejamento curricular e didático. É necessário conhecer e compreender o contexto em que estes alunos se encontram para, então, construir juntos alternativas que possam servir como ferramentas de auxílio na tentativa de atender à legislação da educação indígena.

\section{Contribuição da formação intercultural indígena}

No decorrer desta pesquisa nos deparamos com as demandas e necessidades que levaram à criação do curso, bem como os desafios e avanços que ocorreram durante o processo de formação. Instigados a compreender melhor esta trajetória, finalizamos as entrevistas fazendo o seguinte questionamento: como você compreende a contribuição de uma formação intercultural indígena para a comunidade indígena e não indígena? Os relatos foram similares. Contudo, pequenas diferenças merecem uma análise individual. O(a) professor(a) "A" relata que:

[...] Para a população indígena é muito importante, é uma iniciativa extremamente válida de resgate e justiça social. Estes povos foram expulsos de seus territórios e abatidos severamente. Até hoje eles vivem em uma condição muito diferente, dadas as interferências da cultura não indígena. É uma tentativa de resgate dos valores, da cultura e da linguagem. Em nossa região a relação histórica com os povos indígenas é muito mais sobre o "tirar" do que o "devolver" ou "conviver". Neste sentido, o curso trouxe um pouco mais do "conviver" e tentou devolver a autonomia para as comunidades tradicionais. O curso de formação não resolve tudo neste sentido, mas é um importante passo para que as culturas indígenas percebam seu espaço na sociedade e tenham mais autonomia. [...] Para a sociedade não indígena é importante para que se perceba a necessidade de preservar as culturas tradicionais e aprender a conviver com as diferenças, que tem potencial para agregar muito em nossa forma de viver. É necessário fazer um movimento urgente de políticas públicas para resgatar a cultura Kaingang, que está em iminência de se perder. 
Os relatos anteriores nos mostram que os docentes não receberam capacitação que permitisse conhecer a história regional e se sensibilizar ao contexto indígena. Diante disto, o(a) docente enfatiza a necessidade de resgatar a cultura indígena Kaingang. Quando tratamos de resgatar algo, falamos em retornar ao ponto anterior - neste caso, a fala estaria direcionada ao retorno à cultura indígena pré-conquista? Parece que esta não foi a intenção do comentário. Contudo, é importante notar como ainda é cultural o arquétipo romantizado que idealiza os povos indígenas a partir de aspectos tribais. Neste sentido, o resgate necessário, se é que já houve, seria o da valorização cultural e integração social a partir das experiências interculturais.

Ao questionar o(a) professor(a) "B" sobre a contribuição de uma formação intercultural indígena para a sociedade obtivemos a seguinte resposta:

[...] O curso tem o objetivo de formar professores para escolas indígenas, mas também não indígenas e, neste sentido, é importante citar que estes professores são uma referência para as comunidades onde moram. Então, quanto mais habilitados, capacitados e empoderados com o conhecimento não indígena e resgatando os saberes tradicionais de sua cultura, mais emancipados eles serão para ocupar cada vez mais espaços na sociedade. Outro aspecto importante que o curso sempre buscou é o resgate da língua materna, dando empoderamento para eles referente às questões indígenas para que também possam se defender na sociedade não indígena. Para a comunidade não indígena é importante para que se retome uma consciência de que os indígenas precisam ser considerados na sociedade. Eles são seres humanos como qualquer outro e tem potencial para desenvolver qualquer atividade. Devemos acabar com o pensamento de um "índio" ainda do período colonial, nu e que vive da caça. Este é um estereótipo que não cabe para os dias de hoje; eles vivem e devem viver com os benefícios da vida moderna.

É visível a preocupação do(a) entrevistado(a) diante das mudanças que ocorreram com as culturas indígenas ao longo dos anos, bem como a visão da sociedade não indígena, que trata da cultura indígena de forma romantizada e como uma cultura primitiva. Aqui o(a) docente, assim como no caso anterior, fala em resgate da língua materna dos povos originários. Assim como as sociedades passam por transformações, os idiomas também acompanham estas mudanças. Sem dúvidas, os povos indígenas tiveram suas culturas profundamente alteradas diante do processo de conquista. Desta forma, não é cabível esperar que no período atual eles mantenham os mesmos hábitos ou tenham acessos às mesmas tecnologias do passado. Neste sentido, a utilização da língua materna na educação indígena trata muito mais de valorizar a cultura, promover um ensino contextualizado e significativo. Igualmente, a utilização das 
línguas maternas passa ainda por uma tentativa de promover um suposto reparo histórico diante do impedimento de sua utilização em diversos momentos do período colonial, conforme já descrito nas seções anteriores. Não seria possível, e nem mesmo faria sentido, resgatar o idioma utilizado no passado. Sendo assim, são importantes as reflexões direcionadas cada vez mais à inclusão social, respeitando e valorizando as diferenças culturais.

Referente à mesma pergunta, o(a) professor(a) "C" explica que:

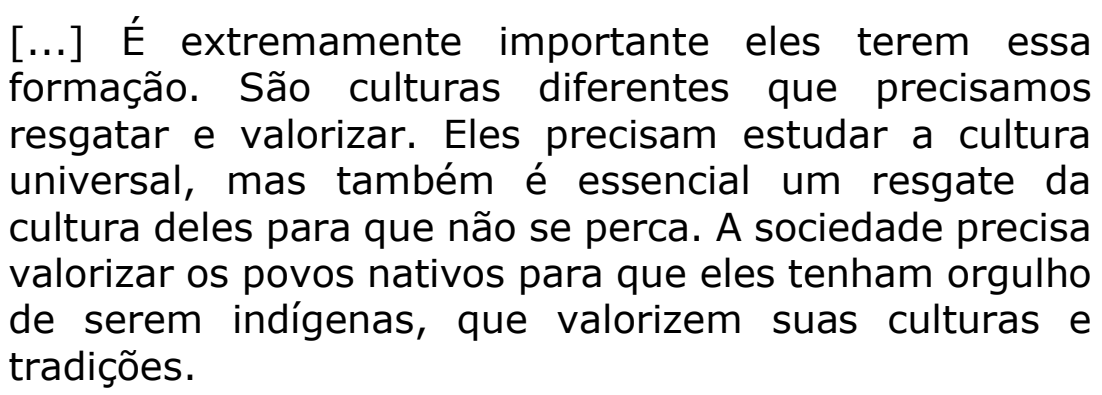

O relato do(a) professor(a) "C" trata novamente do resgate cultural e traz também a importância dos povos indígenas em conhecerem uma suposta cultura universal. Sobre o resgate cultural já foram pontuadas algumas reflexões. Agora, o que seria a cultura universal? Muitas das tradições, costumes e, inclusive, os idiomas foram proibidos de ser durante a conquista. A conquista impôs um movimento civilizatório que definiu o que era permitido ser em todas as esferas da vida sociocultural. Esta resposta expressa como alguns aspectos coloniais ainda se fazem muito presentes, como a suposta ideia de superioridade de uma cultura sobre a outra, de uma racionalidade sobre a outra. Analisando esta fala, é notável que o argumento não está fundamentado de maneira intencional em uma narrativa homogeneizante. Entretanto, demonstra ainda mais a fragilidade que a falta de uma capacitação inicial trouxe para esta modalidade.

\section{Reflexões inacabadas}

Ao finalizar esta escrita, fica a sensação de que algo importante foi feito. Porém, muito ainda precisa ser percorrido. O sentimento de que estamos só começando nos coloca em um lugar de responsabilidade, mas principalmente de diálogo e ação.

O curso de Licenciatura Intercultural Indígena da Unochapecó, conforme mencionado na introdução, é precursor no sul do Brasil em formar professores indígenas em terras indígenas. Contudo, conforme as falas dos professores deixam patente, os desafios foram muitos. Diante dos relatos coletados, alguns aspectos coloniais estiveram presentes nas percepções dos(as) docentes. Com isso, enfatizamos que uma formação de capacitação inicial seria oportuna e se mostrou necessária. Entretanto, ficou evidente que, ao promover esta experiência em terras indígenas, realizou-se, em alguma medida, também, a alfabetização intercultural dos 
docentes, que puderam ser sensibilizados para esta temática no decorrer do processo formativo.

Os desafios de uma formação intercultural indígena são muitos. É preciso estreitar ainda mais o diálogo com as comunidades e pensar a construção de novas iniciativas conjuntas. Durante as entrevistas ficou evidente que a construção do curso foi importante, mas apresentou fragilidades na compreensão da proposta intercultural. Igualmente, as condições de infraestrutura dos espaços de ensino das comunidades possivelmente não foram levadas em consideração. Com isso, evidenciase a necessidade de mais ações por parte do poder público e investimentos nestas comunidades para oportunizar melhores condições de acesso à informação.

A experiência relatada aqui é extremamente importante para as comunidades indígenas da região e vislumbra a emancipação e valorização cultural dos povos tradicionais. A comunidade não indígena precisa cada vez mais estar integrada aos povos indígenas do Brasil e, a partir desta relação, compartilhar saberes e experiências mútuas, respeitando as diferenças entre ambos. Esperamos que esta pesquisa possa servir como exemplo para outras experiências de formação intercultural, contribuindo para a melhora dos processos de construção e execução de novos projetos que possam vir a surgir. 
Espaço Ameríndio

\section{Referências bibliográficas}

BRASIL. SECRETARIA DE EDUCAÇÃO FUNDAMENTAL. Referencial curricular nacional para as escolas indígenas. Ministério da Educação e do Desporto, Secretaria de Educação Fundamental, 1998.

BRIGHENTI, Clovis Antônio. Povos indígenas em Santa Catarina. Etnohistória, história indígena e educação: contribuições ao debate, p. 37-65, 2012.

CANDADO, Rejane Aparecida Rodrigues. Referencial Curricular Nacional para Escolas Indígenas: Cultura e Conhecimento no Ensino de História. 2006. 111 f. Dissertação (Mestrado em Educação) - Universidade Católica Dom Bosco - Campo Grande - MS.

CARBONERA, Mirian; SCHMITZ, Pedro Ignacio. Antes do oeste catarinense: arqueologia dos povos indígenas. Chapecó: Argos, 2011.

D'ANGELIS, Wilmar R. Para uma história dos índios do oeste catarinense. Revista Cadernos do Ceom, v. 19, n. 23, p. 265-343, 2014.

DA CUNHA, Manuela Carneiro. Índios no Brasil: história, direitos e cidadania. Editora Companhia das Letras, 2013.

DA CUNHA, Manuela Carneiro. História dos índios no Brasil. Editora Schawarcz, 2002.

DE ALMEIDA, A. G. Educação e evangelização: a convivência de jesuítas e índios no século XVI no brasil. Tese (Doutorado em Educação) - Universidade Metodista de Piracicaba, Piracicaba, 2016.

DUSSEL, Enrique. 1492 O encobrimento do outro: a origem do mito da modernidade. 1. ed. Petrópolis: Vozes, 1993. 196 p. v. 1. ISBN 85-326-1045-5

GARCIA, Elisa Frühauf. O projeto pombalino de imposição da língua portuguesa aos índios e a sua aplicação na América meridional. Revista Tempo, v. 12, n. 23, p. 23-38, 2007.

GALEANO, Eduardo h. As veias abertas da América latina. Tradução de Sérgio Faraco. Porto Alegre: L\&Pm, 2018.

GRUPIONI, Luís Donisete Benzi. Programa Parâmetros em Ação-Educação Escolar Indígena. Ministério da Educação, Secretaria de Educação Fundamental, 2002.

GUTIÉRREZ, J. L. A controvérsia de Valladolid (1550): Aristóteles, os índios e a guerra justa. Revista USP, [S. l.], n. 101, p. 223-235, 2014. DOI: 10.11606/issn.23169036.v0i101p223-235.

IBGE. Indígenas (IBGE). [S. 1.], 2019. Disponível em: https://indigenas.ibge.gov.br. Acesso em: 21 maio 2019. 
MELATTI, Julio Cezar. De Nóbrega a Rondon. Revista de Atualidade Indígena, ano, v. 1, p. 38-45, 1977.

MIGNOLO, Walter. Colonialidade: o lado mais escuro da modernidade. Revista Brasileira de Ciências Sociais, 32(94), 1-17, 2017.

MOONEN, Frans. Povos indígenas no Brasil. Antropologia, n. 01, p. 25-42, 2008.

NETO, Alexandre Shigunov; MACIEL, Lizete Shizue Bomura. O ensino jesuítico no período colonial brasileiro: algumas discussões. Educar em revista, v. 24, n. 31, p. 169189, 2008.

QUIJANO, Aníbal. Colonialidad del poder: Eurocentrismo y América Latina. In: LANDER, Edgardo. La Colonialidad del saber: Eurocentrismo y ciencias sociales: perspectivas latinoamericanas. 1. ed. Buenos Aires: CLACSO, 2000. v. 1, p. 201-246. ISBN 950-9231-51-7.

SANTOS, Jorge Alejandro; PIOVEZANA, Leonel; DOS SANTOS BERNARDI, Luci Teresinha Marchiori. Colonialidad y descolonización en la educación latinoamericana: el caso de las licenciaturas interculturales indígenas con el Pueblo Kaingang. Eccos, n. 45, p. 59, 2018.

SAVIANI, Dermeval. História das ideias pedagógicas no Brasil. Autores Associados, 2013.

SECO, Ana Paula; AMARAL, Tania Conceição Iglesias do. Marquês de Pombal e a reforma educacional brasileira. Faculdade de educação da UNICAMP, São Paulo, 2006.

SOLANO-ALPÍZAR, J. Decolonizing Education or Accepting the Challenge of Taking a Different Path. Revista Electrónica Educare, v. 19, n. 1, p. 117-129, 1 jan. 2015.

UNOCHAPECÓ. Projeto Pedagógico Do Curso De Graduação Em Licenciatura Intercultural Indígena. Chapecó, p. 1-53, 2009.

VAINFAS, Ronaldo. A heresia dos índios - catolicismo e rebeldia no Brasil Colonial. São Paulo, Companhia das Letras, 1995.

VEIGA, J. Cosmologia e práticas rituais Kaingang. 2000. 367 p. Tese (doutorado em antropologia social). Instituto de Filosofia e Ciências Humanas. Universidade Estadual de Campinas, São Paulo, 2000.

VEIGA, J. Organização social e cosmovisão Kaingang: uma introdução ao parentesco, casamento e nominação em uma sociedade Je meridional. 1994. [226] f. Dissertação (mestrado em antropologia social) - Universidade Estadual de Campinas, Instituto de Filosofia e Ciências Humanas, Campinas, SP. 
Recebido em: 04/04/2021* Aprovado em: 12/12/2021 * Publicado em: 23/12/2021 